\title{
Thermogravimetric and Spectroscopic Analysis of 8-Hydroxyquinoline 5-Sulphonic Acid-melamine-formaldehyde Polymer Resin-IV
}

\author{
Rajesh N. Singru \\ R.D College of Science, Aheri, Gadchiroli, Nagpur, Maharashtra 442705, India \\ Correspondence should be addressed to Rajesh N. Singru, rajeshsingru@in.com
}

Received 11 December 2011; Accepted 2 January 2012

Academic Editors: Y. Fang, E. Gallicchio, S. Hashimoto, and P. Trens

Copyright (C) 2012 Rajesh N. Singru. This is an open access article distributed under the Creative Commons Attribution License, which permits unrestricted use, distribution, and reproduction in any medium, provided the original work is properly cited.

\begin{abstract}
The title terpolymer (8-HQ5-SAMF-IV) synthesized by the condensation of 8-hydroxyquinoline 5-sulphonic acid (8-HQ5-SA) and melamine $(\mathrm{M})$ with formaldehyde $(\mathrm{F})$ in the presence of acid catalyst and using varied $3: 1: 5$ molar proportions of the reacting monomers. The synthesized terpolymer was characterized by different physicochemical techniques. The thermogravimetric analysis of terpolymer resin prepared in the present study has been carried out by nonisothermal thermogravimetric analysis technique in which sample is subjected to condition of continuous increase in temperature at linear rate. Thermal study of the resin was carried out to determine the mode of decomposition and thermal stability. Thermal decomposition curve was studied carefully with minute details. The Freeman-Carroll and Sharp-Wentworth methods have been used in the present investigation to calculate thermal activation energy and different kinetic parameter of the terpolymer resin. Thermal activation energy $\left(E_{\mathrm{a}}\right)$ calculated by two above mentioned methods, is in close agreement. The advantage of Freeman-Carroll method is to calculate both the order of reaction $(n)$ and energy of activation in one single stage by keeping heating rate constant. By using data of thermogravimetric analysis, various thermogravimetric parameters like frequency factor $(Z)$, entropy change $(\Delta S)$, free energy change $(\Delta F)$, and apparent entropy $\left(S^{*}\right)$ have been determined using Freeman-Carroll method.
\end{abstract}

\section{Introduction}

The synthesized terpolymer resins, showing versatile applications and properties, attracted the attention of scientist and introduced the recent innovations in the polymer chemistry. These terpolymers can be used as high-energy material [1], ion-exchanger [2], semiconductors [3], antioxidants, fire proofing agent, optical storage data, binders, molding materials, and so forth. Literature survey reveals the chelation ion-exchange properties of 2, 4-dinitrophenylhydrazone of 2-hydroxyacetophenone-formaldehyde resin [4], and oximes of 2-hydroxyacetophenone-substituted benzoic acidformaldehyde resin [5] for different metal ions. Thermogravimetric analysis of urea-formaldehyde polycondensate (UFPS) has been reported by Zeman and Tokarova [6]. Terpolymer resins having good thermal stability have enhanced the scope for development of some polymeric materials. The study of the thermal degradation of terpolymer resins have recently become a subject of interest. Hong et al. studied the thermal decomposition behaviour of phosphorous containing copolyester [7]. In an earlier communication [8-11] from this department, numbers of studies on such terpolymers have been reported. However, no work seems to have been carried out on synthesis, characterization, and thermal stabilities of the terpolymer resins-IV from 8-hydroxyquinoline 5 -sulphonic acid-melamine and formaldehyde. The present paper describes the composition of newly synthesized resin, its characterization by elemental analysis, average molecular weight $(\bar{M} n)$, determination of intrinsic viscosity in DMSO, FTIR Spectra, UV-Visible absorption spectra, NMR spectra, and thermal analysis by applying the Sharp-Wentworth and Freeman-Carroll methods. Energy of activation $\left(E_{\mathrm{a}}\right)$, kinetic parameter namely, $Z, \Delta S, \Delta F, S^{*}$, and order of reaction $(n)$ were determined by applying the Freeman-Carroll method. 


\section{Experimental}

2.1. Materials. The chemicals used in the synthesis of new terpolymer resin were procured from the market and were analar or Fulka or chemically pure grade. Whenever required, they were further purified by standard procedure.

2.2. Synthesis of 8-HQ5-SAMF-IV Terpolymer. The new terpolymer resin 8-HQ5-SAMF-IV was synthesized by condensing 8-hydroxyquinoline 5 -sulphonic acid $(0.4 \mathrm{~mol})$ and melamine $(0.2 \mathrm{~mol})$ with $37 \%$ formaldehyde $(0.7 \mathrm{~mol})$ in a mol ratio of $4: 2: 7$ in the presence of $2 \mathrm{M} 200 \mathrm{~mL} \mathrm{HCl}$ as a catalyst at $140^{\circ} \mathrm{C} \pm 2^{\circ} \mathrm{C}$ for $6 \mathrm{~h}$ in an oil bath with occasional shaking to ensure thorough mixing. The separated terpolymer was washed with hot water and methanol to remove unreacted starting materials and acid monomers. The properly washed resin was dried, powdered, and then extracted with diethyl ether and then with petroleum ether to remove 8-hydroxyquinoline 5-sulphonic acid formaldehyde copolymer which might be present along with 8-HQ5SAMF-IV terpolymer. The yellow colour resinous product was immediately removed from the flask as soon as reaction period was over and then purified. The reaction and suggested structure of 8-HQ5-SAMF-IV is shown in Figure 1.

The terpolymer was purified by dissolving in $10 \%$ aqueous sodium hydroxide solution, filtered, and reprecipitated by gradual dropwise addition of ice-cold $1: 1(\mathrm{v} / \mathrm{v})$ concentrated hydrochloric acid/distilled water with constant and rapid stirring to avoid lump formation. The process of reprecipitation was repeated twice. The terpolymer sample 8-HQ5-SAMF-IV thus obtained was filtered, washed several times with hot water, dried in air, powdered, and kept in vacuum desiccator over silica gel. The yield of the terpolymer resin was found to be $76 \%$. The elemental analysis is tabulated in Table 1.

\section{Characterization}

The viscosities were determined using Taun-Fuoss viscometer at six different concentrations ranging from 1.00 to $0.031 \%$ of terpolymer in DMSO at $30^{\circ} \mathrm{C}$. The intrinsic viscosity $\eta$ was calculated by relevant plots of the Huggins' equation and Kraemmer's equation:

$$
\begin{gathered}
\frac{\eta_{\mathrm{sp}}}{\mathrm{C}}=[\eta]+\mathrm{K}_{1}[\eta]^{2} \mathrm{C}, \\
\frac{\ln \eta_{\mathrm{rel}}}{\mathrm{C}}=[\eta]+\mathrm{K}_{2}[\eta]^{2} \mathrm{C} .
\end{gathered}
$$

The number average molecular weight $(\bar{M} n)$ was determined by conductometric titration in nonaqueous medium such as dimethylsulphoxide (DMSO) using ethanolic $\mathrm{KOH}$ as a titrant. From the graph of specific conductance against milliequivalents of base, first and last break were noted from which degree of polymerisation $(\overline{D P})$ and the number average molecular weight $(\bar{M} n)$ has been calculated for terpolymer resin.
Electron absorption spectrum of terpolymer resin was recorded in DMSO (spectroscopic grade) on Shimadzu double beam spectrophotometer in the range of 200 to $850 \mathrm{~nm}$. An infrared spectrum of 8-HQ5-SAMF-IV terpolymer resin was recorded on Perkin-Elmer-983 spectrophotometer in $\mathrm{KBr}$ pallets in the wave number region of $4000-400 \mathrm{~cm}^{-1}$. A nuclear magnetic resonance (NMR) spectrum of newly synthesized terpolymer resin has been scanned on Bruker Advanced 400 NMR spectrometer using DMSO- $\mathrm{d}_{6}$. TGA of terpolymer resin has been carried out by using Perkin-Elmer TGS-II Thermogravimetric Analyzer at heating rate of $10^{\circ} \mathrm{C}$ per minute up to $800^{\circ} \mathrm{C}$.

\section{Results and Discussion}

The newly synthesized and purified 8-HQ5-SAMF-IV terpolymer resin was found to be yellow in colour. The terpolymer is soluble in solvents such as DMF, DMSO, and THF while insoluble in almost all other organic solvents. The melting point of the terpolymer was determined by using electrically heated melting point apparatus and is found to be in $392 \mathrm{~K}$. This resin was analyzed for carbon, hydrogen, nitrogen, and sulphur content. The details of elemental analysis are incorporated in Table 1 . The terpolymer which has been used in the present investigation was prepared by the reaction given in Figure 1.

The number average molecular weight $(\bar{M} n)$ of the terpolymer has been determined by conductometric titration method in nonaqueous medium and using standard potassium hydroxide $(0.05 \mathrm{M})$ in absolute ethanol as a titrant. The result is presented in Table 1 . The specific conductance was plotted against milliequivalents of ethanolic $\mathrm{KOH}$ required for neutralization of $100 \mathrm{gm}$ of each terpolymer. There are several breaks before the complete neutralization of all phenolic hydroxyl groups. The first break in the plot was the smallest break and assumed that this corresponds to a stage in titration when an average one phenolic hydroxy group of each chain was neutralized.

From the plot (Figure 2) the first and last break was noted. The average degree of polymerization $(\overline{D P})$ and hence the number average molecular weights $(\bar{M} n)$ of terpolymer has been determined using the following formula $[12,13]$ :

$(\overline{D P})=$ Total milliequivalents of base required for complete neutralisation/Milliequivalents of base required for smallest interval $(\bar{M} n)=(\overline{D P}) \times$ Repeat unit weight.

The intrinsic viscosity $[\eta]$ was determined by the corresponding linear plots. Huggins' and Kraemmer's constants were determined by expressions 1 and 2 .

According to the above relations, the plots (Figure 3 ) of $\eta_{\mathrm{sp}} / C$ and $\ln \eta_{\text {rel }} / C$ against $C$ were linear with slopes of $K_{1}$ and $K_{2}$, respectively. By extrapolating linear plot to zero concentration, intercepts on the viscosity function axis give $[\eta]$ value in both plots.

Values of intrinsic viscosity obtained from both plots have been found to be closed agreement with each other. The calculated values of the constants $K_{1}$ and $K_{2}$ in most cases satisfy the relation $K_{1}+K_{2}=0.5$ favorably [14]. It was observed that terpolymer having higher $(\bar{M} n)$ shows 

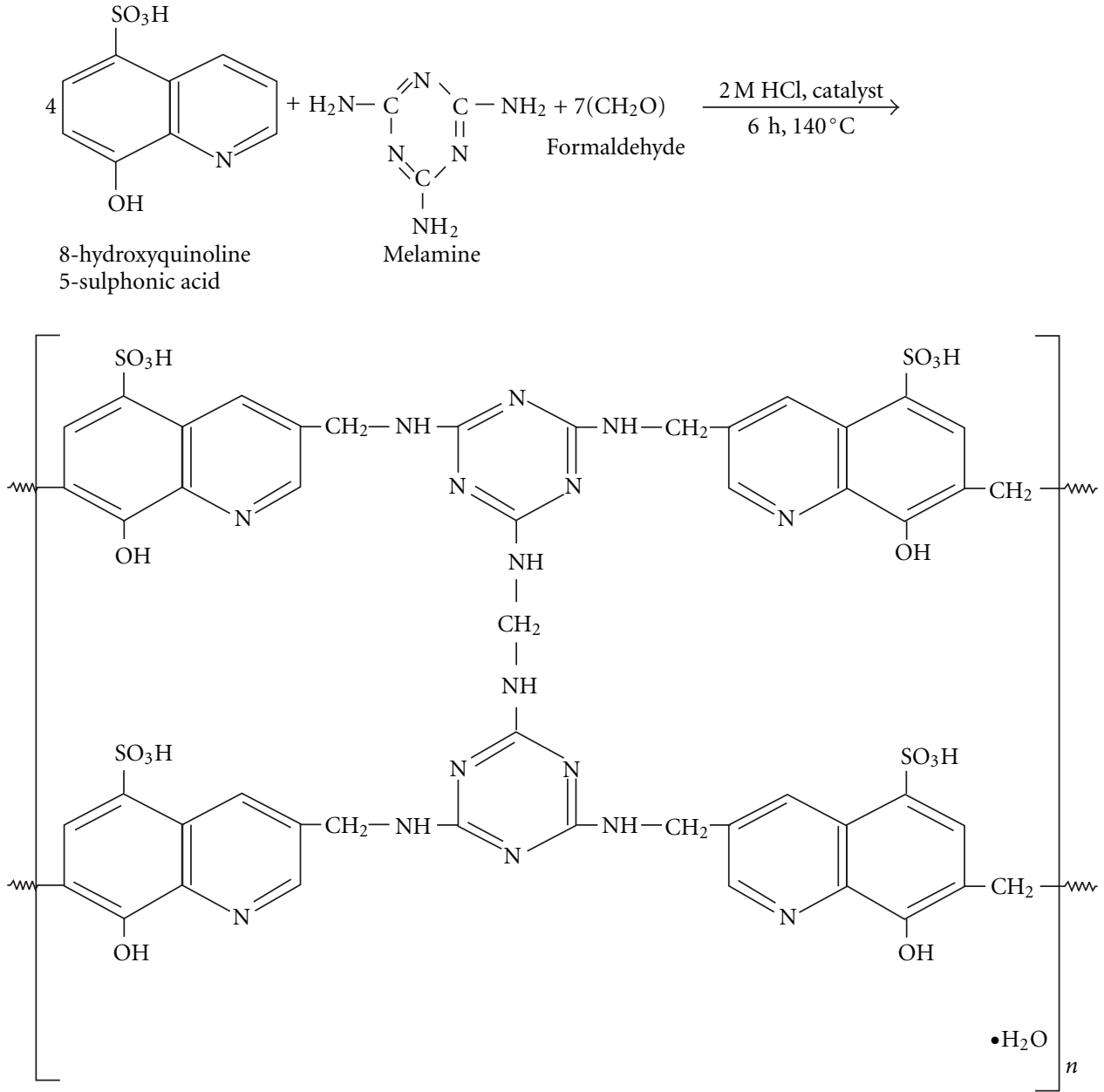

FIGURE 1: Reaction and expected structure of 8-HQ5-SAMF-IV terpolymer resin.

TABLE 1: Elemental analysis, molecular weight determination, and intrinsic viscosity of 8-HQ5-SAMF-IV terpolymer resin.

\begin{tabular}{|c|c|c|c|c|c|c|c|c|}
\hline \multirow{3}{*}{$\begin{array}{l}\text { Empirical } \\
\text { formula of } \\
\text { repeat unit }\end{array}$} & \multirow{3}{*}{$\begin{array}{l}\text { Empirical weight } \\
\text { of repeat unit } \\
(\mathrm{gm})\end{array}$} & \multirow{3}{*}{$\begin{array}{l}\text { Average degree of } \\
\text { polymerization } \\
(\overline{D P})\end{array}$} & \multirow{3}{*}{$\begin{array}{l}\text { Average } \\
\text { molecular } \\
\text { weight }(\bar{M} n)\end{array}$} & \multicolumn{4}{|c|}{$\begin{array}{c}\text { Elemental analysis } \\
\text { Percentage }(\%) \text { of element }\end{array}$} & \multirow{3}{*}{$\begin{array}{l}\text { Intrinsic } \\
\text { viscosity } \\
{[\eta](\mathrm{d} 1 / \mathrm{g})}\end{array}$} \\
\hline & & & & $\mathrm{C}$ & $\mathrm{H}$ & $\mathrm{N}$ & S & \\
\hline & & & & $\begin{array}{c}\text { Found } \\
\text { (Cal.) }\end{array}$ & $\begin{array}{r}\text { Found } \\
\text { (Cal.) }\end{array}$ & $\begin{array}{c}\text { Found } \\
\text { (Cal.) }\end{array}$ & $\begin{array}{l}\text { Found } \\
\text { (Cal.) }\end{array}$ & \\
\hline $\mathrm{C}_{55} \mathrm{H}_{45} \mathrm{~N}_{11} \mathrm{O}_{21} \mathrm{~S}_{5}$ & 1355 & 15.5 & 21002 & $48.15(48.1)$ & $2.68(3.32)$ & $10.79(11.3)$ & $11.25(11.80)$ & 1.31 \\
\hline
\end{tabular}

higher value of $[\eta]$ which is in good agreement with earlier coworkers $[14,15]$.

The UV-Visible spectra (Figure 4) of the 8-HQ5-SAMFIV terpolymer sample in pure DMSO was recorded in the region $200-850 \mathrm{~nm}$ at a scanning rate of $100 \mathrm{~nm} \cdot \mathrm{min}^{-1}$ and a chart speed of $5 \mathrm{~cm} \cdot \mathrm{min}^{-1}$. The 8-HQ5-SAMF-IV terpolymer sample gave two characteristics bands at 360$370 \mathrm{~nm}$ and $240-260 \mathrm{~nm}$. These observed positions for the absorption bands have different intensities. The more intense band is due to $\pi \rightarrow \pi^{*}$ transition and the less intense is due to $n \rightarrow \pi^{*}$ transition. The $\pi \rightarrow \pi^{*}$ transition indicates the presence of aromatic nuclei, and $n \rightarrow \pi^{*}$ transition indicates presence of $-\mathrm{NH}$ and $-\mathrm{OH}$ group. The hyperchromic effect is due to the presence of $-\mathrm{OH}$ and $-\mathrm{NH}$ groups, which act as auxochrome [16].

The IR (Figure 5) spectral studies revealed that the terpolymer gave broad absorption band appeared in the region $3506-3508 \mathrm{~cm}^{-1}$ may be assigned to the stretching vibrations of phenolic hydroxyl (-OH) groups exhibiting intramolecular hydrogen bonding [17]. A sharp strong peak at $1556-1626 \mathrm{~cm}^{-1}$ may be ascribed to aromatic skeletal ring. The bands obtained at $1210-1230 \mathrm{~cm}^{-1}$ suggest the presence of methylene $\left(-\mathrm{CH}_{2}\right)$ bridge [18]. The $1,2,3,5$ substitution of aromatic benzene ring recognized by the sharp, medium/weak absorption bands appeared at 953-970, 1145-1046, 1182-1188, and 1320-1321 cm ${ }^{-1}$, respectively. 


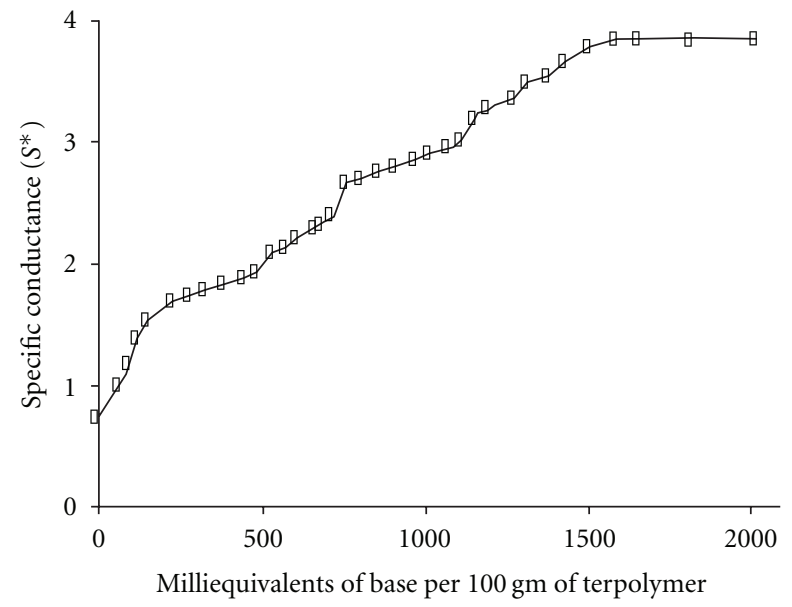

Figure 2: Conductometric titration curve of 8-HQ5-SAMF-IV resin.

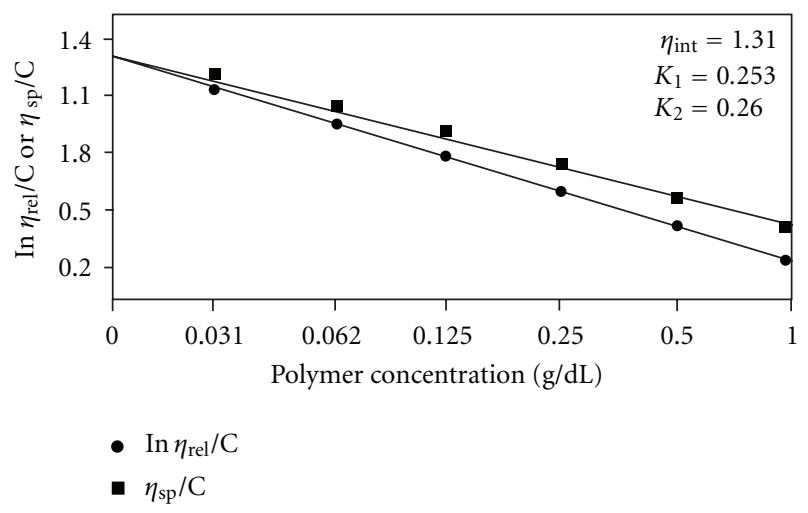

FIGURE 3: Viscometric curves of 8-HQ5- SAMF-IV terpolymer resin.

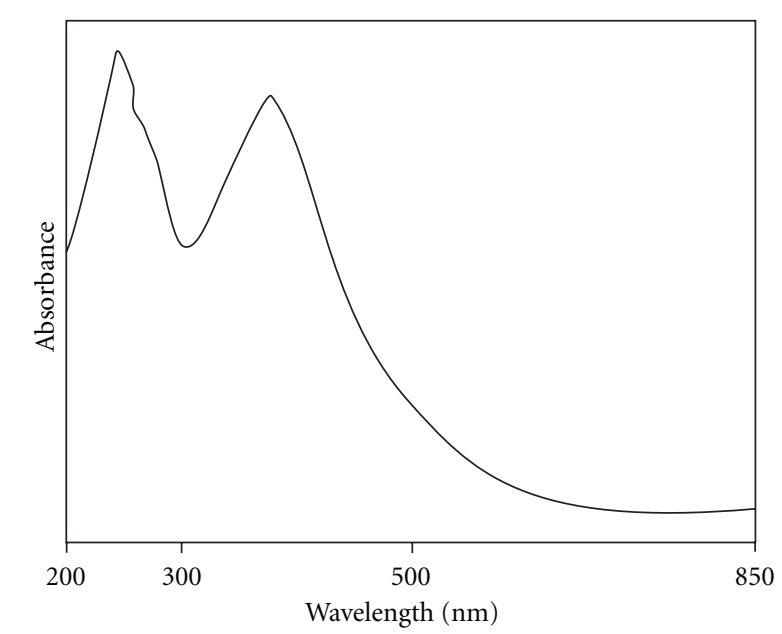

Figure 4: Uv-Visible spectrum of 8-HQ5-SAMF-IV terpolymer resin.

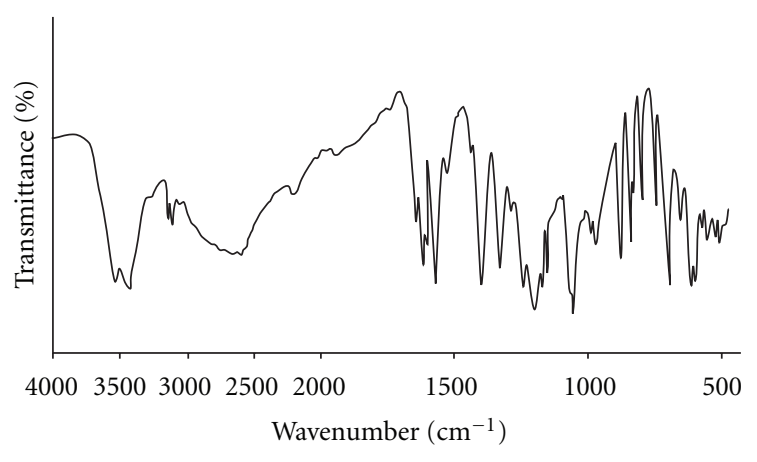

FIGURE 5: IR spectrum of 8-HQ5-SAMF-IV terpolymer resin.

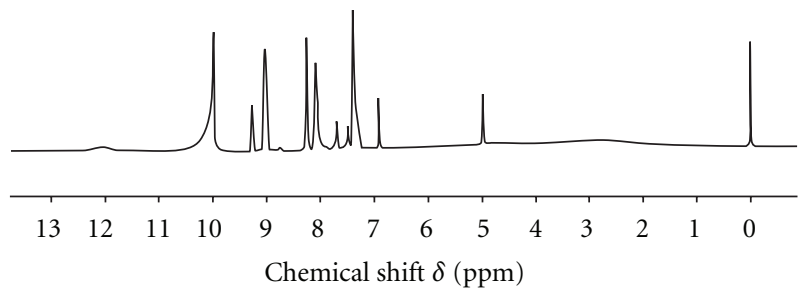

FIGURE 6: NMR spectrum of 8-HQ5-SAMF-IV terpolymer resin.

The presence of sharp and strong band at $3393-3402 \mathrm{~cm}^{-1}$ indicates the presence of $-\mathrm{NH}$ bridge. This band seems to be merged with very broad band of phenolic hydroxyl group.

The NMR spectrum (Figure 6) of 8-HQ5-SAMF-IV terpolymer was scanned in DMSO- $\mathrm{d}_{6}$ solvent. The chemical shift $(\delta)$ ppm observed is assigned on the basis of data available in the literature $[19,20]$. The singlet obtained in the region 4.98-4.96 $(\delta) \mathrm{ppm}$ may be due to the methylene proton of $\mathrm{Ar}-\mathrm{CH}_{2}-\mathrm{N}$ moiety. The signal in the region of $7.35-7.41(\delta) \mathrm{ppm}$ is attributed to protons of $-\mathrm{NH}$ bridge. The weak multiplate signals (unsymmetrical pattern) in the region of $8.25-8.20(\delta) \mathrm{ppm}$ may be attributed to aromatic proton $(\mathrm{Ar}-\mathrm{H})$. The signal in the range at 9.02 to $9.06(\delta) \mathrm{ppm}$ may be due to phenolic hydroxyl protons. The much downfield chemical shift for phenolic -OH indicates clearly the intramolecular hydrogen bonding of $-\mathrm{OH}$ group $[20,21]$. The signals in the range of 9.96-9.92 $(\delta)$ ppm are attributed to proton of $-\mathrm{SO}_{3} \mathrm{H}$ groups.

The polymer under study is terpolymer and, hence, it is very difficult to assign the exact structure. However, on the basis of the nature and reactive site of the monomers and taking into consideration the linear structure of other substituted phenol formaldehyde polymers and the linear branched nature of urea-formaldehyde polymers the most probable structure [22] of proposed for 8-HQ5-SAMF-IV terpolymer has been depicted in Figure 1, showing linear branch structure.

4.1. Thermogravimetry. Thermogravimetry of 8-HQ5SAMF-IV terpolymer resin has been carried out using Perkin-Elmer thermogravimetric analyser. A brief account of thermal behavior of 8-HQ5-SAMF-IV terpolymer is given in Figures 7-9. 


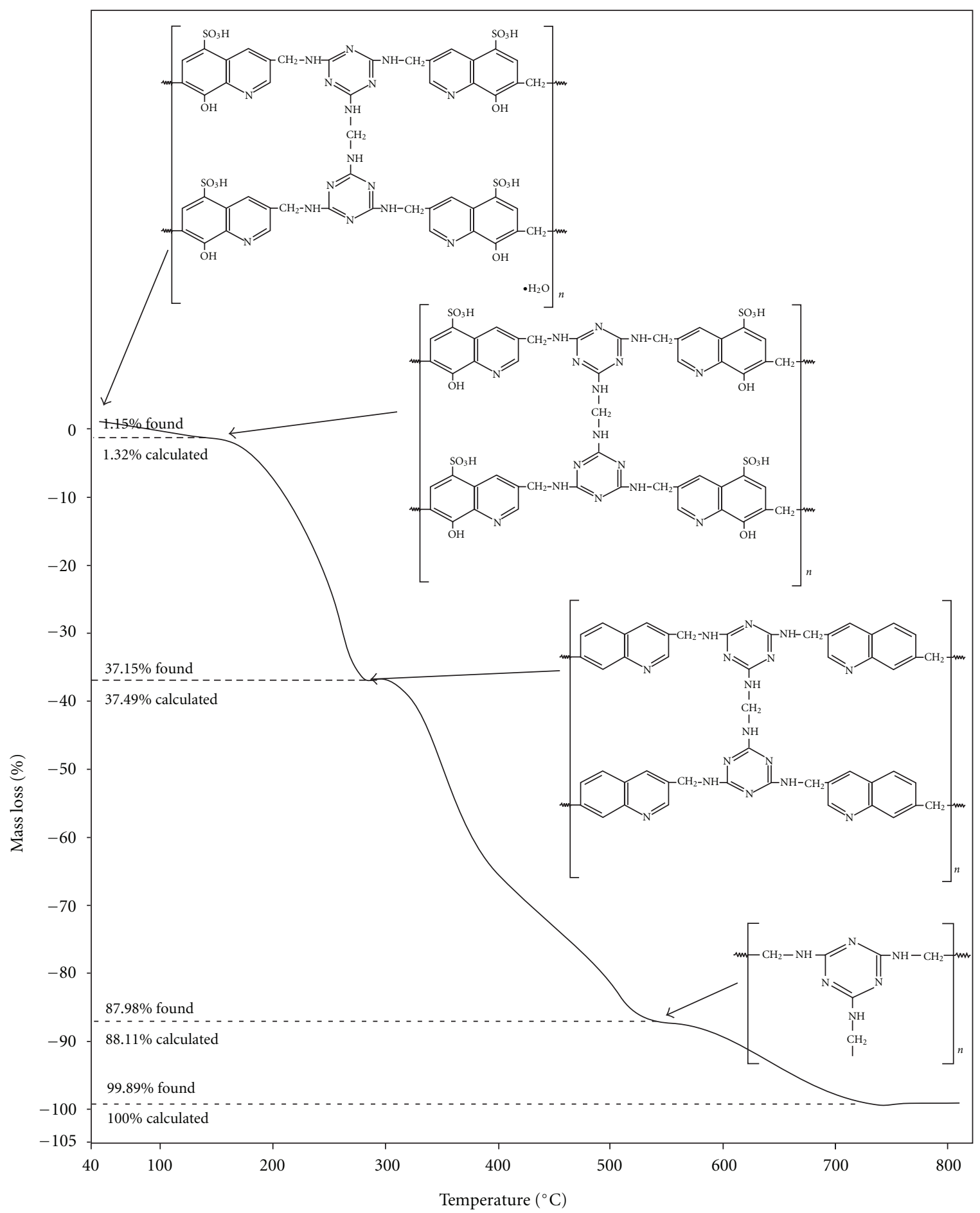

FIgURe 7: Decomposition pattern of 8-HQ5-SAMF-IV terpolymer resin.

TABLE 2: Results of thermogravimetric analysis of 8-HQ5-SAMF-IV terpolymer resin.

\begin{tabular}{cccccccc}
\hline Terpolymer resin & $\begin{array}{c}\text { Half } \\
\text { decomposition } \\
\text { temp. (K) }\end{array}$ & Activation energy (KJ/mol) & $\begin{array}{c}\text { Entropy change } \\
-\Delta S(\mathrm{~J} / \text { degree })\end{array}$ & $\begin{array}{c}\text { Free energy } \\
\text { change } \Delta F \\
(\mathrm{KJ} / \mathrm{mol})\end{array}$ & $\begin{array}{c}\text { Frequency } \\
\text { factor } Z \\
\left(\mathrm{sec}^{-1}\right)\end{array}$ & $\begin{array}{c}\text { Apparent } \\
\text { entropy } S^{*} \\
(\mathrm{~J})\end{array}$ & $\begin{array}{c}\text { Order of } \\
\text { reaction } \\
\text { found }(n)\end{array}$ \\
\hline 8-HQ5-SAMF-IV & 653 & FC & $\mathrm{SW}$ & -160.9 & 109.7 & 780 & -19.1 \\
\hline
\end{tabular}

FC = Freeman-Carroll, SW = Sharp-Wentworth . 


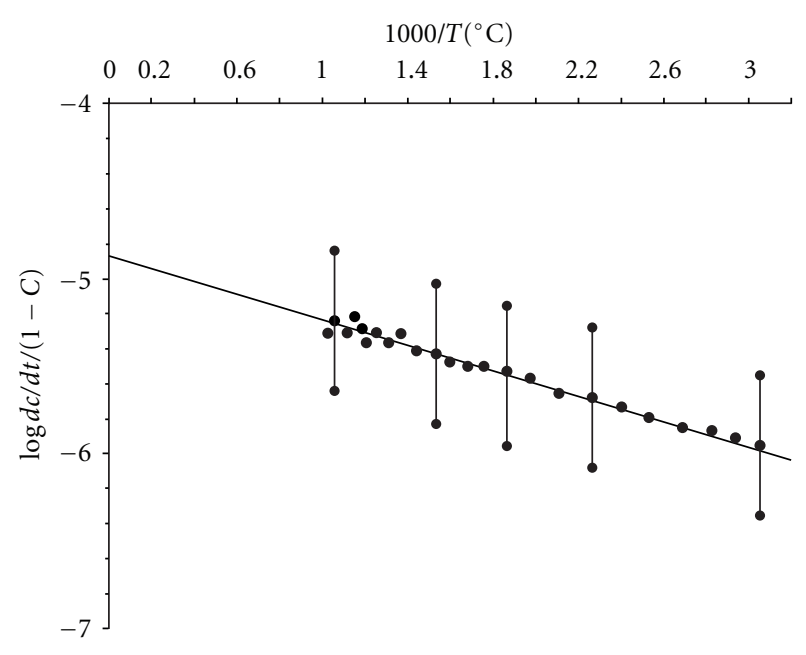

FIGURE 8: Sharp-Wentworth plot of 8-HQ5-SAMF-IV terpolymer resin.

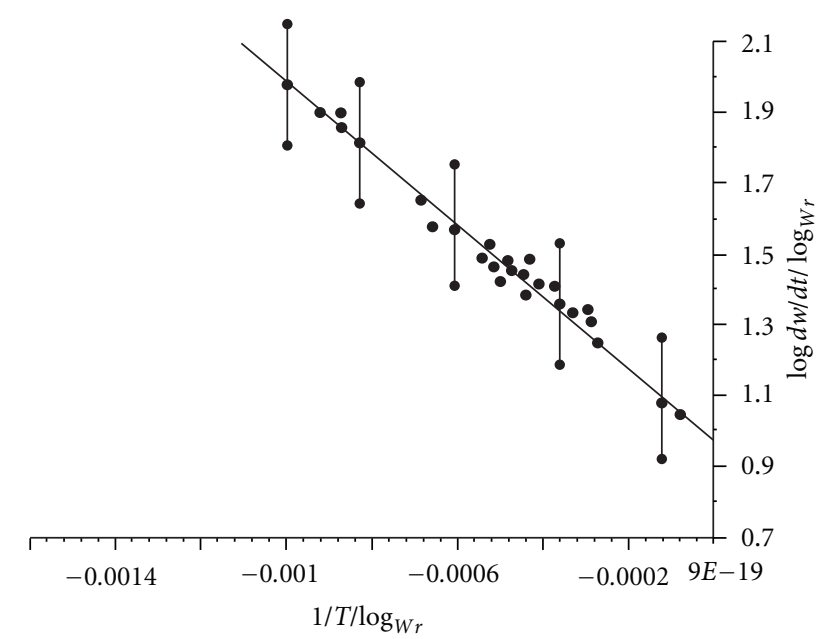

FIGURE 9: Freeman-Carroll plot of 8-HQ5-SAMF-IV terpolymer resin.

4.2. TG of 8-HQ5-SAMF-IV Terpolymer. Decomposition pattern of 8-HQ5-SAMF-IV terpolymer resin has been shown in Figure 7. Examination of thermogram found that the terpolymer under investigation is resistance to elevated temperature. From TG, the thermal degradation has been studied in four temperature ranges $\left(40-180^{\circ} \mathrm{C}\right.$, $180-300^{\circ} \mathrm{C}, 300-560^{\circ} \mathrm{C}, 560-800^{\circ} \mathrm{C}$ ). The initial weight loss of $1.15 \%$ found and $1.32 \%$ calculated at $40-180^{\circ} \mathrm{C}$ may be attributed due to removal of water in the form of moisture retained in the sample during synthesis. In the first stage of thermal degradation $\left(180-300^{\circ} \mathrm{C}\right)$, four hydroxyl groups and four sulphonic groups become activated due to increasing thermal vibration in the molecule, so recross linking occurs and develops a strain in the macromolecule, increasing instability and losses in the fine structure of the sample, resulting in a loss of four hydroxyl and sulphonic groups (37.18\% found and $36.98 \%$ calculated). In the second stage of thermal degradation $\left(300-560^{\circ} \mathrm{C}\right)$, due to increasing temperature the strain in the molecule increases which increases instability more, and causes the mass loss corresponding to $87.98 \%$ found and $88.11 \%$ calculated, equivalent to the decomposition of four aromatic quinoline rings. In the third stage of thermal decomposition (560$800^{\circ} \mathrm{C}$ ) the strained in the macromolecule suffer high crosslinking and depolymerization occurs. This causes the weight loss of about $99.89 \%$ found and $100 \%$ calculated and may be due to degradation of $1,3,5$ triazine ring with its side chain. The rest of the part after complete degradation is the residue, which was found negligible.

In the present investigation Sharp-Wentworth and Freeman-Carroll methods have been used to determine the kinetic parameters of 8-HQ5-SAMF-IV terpolymer sample.

4.3. Sharp-Wentworth Method. In this method the following expression is used:

$$
\log \left[\frac{d c / d t}{\Delta(1-c)}\right]=\log \left(\frac{A}{\beta}\right)-\frac{E_{\mathrm{a}}}{2.303 \mathrm{R}}-\frac{1}{T},
$$

where $\beta$ is the linear heating rate. The graph of $\log [(d c / d t) / \Delta(1-c)]$ versus $1 / T$ has been plotted. The graph is a straight line with $E_{\mathrm{a}}$ as slope and $A$ as intercept. The linear relationship confirms that the assumed order $(n)=1$ is correct.

4.4. Freeman-Carroll Method. In this method the following expression is used:

$$
\frac{\Delta \log (d w / d t)}{\Delta \log W_{r}}=\left(-\frac{E_{\mathrm{a}}}{2.303} \mathrm{R}\right)-\frac{\Delta(1 / T)}{\Delta \log W_{r}}+n,
$$

where $(d w / d t)=$ rate of change of weight of terpolymer sample with respect to time $W_{r}=W_{c}-W$, where $W_{c}$ is the weight loss at the completion of the terpolymer reaction or at definite time and $W$ is the total weight loss upto time $t$.

$T$ is the temperature, $\mathrm{R}$ is the gas constant, and $\mathrm{n}$ is the order of reaction.

Hence the graph of $(\Delta \log (d w / d t)) /\left(\Delta \log W_{r}\right)$ versus $\Delta(1 / T) /\left(\Delta \log W_{r}\right)$ should give on $Y$ axis $(x=0)$ an intercept for the value of $n$, the order of reaction, and the slope $m=-E_{\mathrm{a}} / 2.303 \mathrm{R}$. The detailed procedure is clearly laid out for one representative sample as an illustration.

A plot of percentage mass loss versus temperature has been shown in Figure 7 for 8-HQ5-SAMF-IV terpolymer. From this curve, initial and half decomposition temperatures were determined (Table 2), which can explain the thermal stability of the polymer, neglecting the degree of decomposition (Table 2).

Using thermal decomposition data and applying the Sharp-Wentworth method Figure 8, activation energy is calculated which is in agreement with the activation energy calculated by Freeman-Carroll method, Figure 9 [22]. Thermodynamic parameters such as entropy change $(\Delta S)$, free energy change $(\Delta F)$, frequency factor $(Z)$, and apparent entropy $\left(S^{*}\right)$ calculated on the basis of thermal activation energy are given in Table 2 . Using equations given below, all thermodynamic parameters have been calculated: 
(i) Entropy change

$$
\text { Intercept }=\log \frac{K \mathrm{R}}{h \Phi E}+\frac{\Delta S}{2.303 R},
$$

where, $K=1.3806 \times 10^{-16} \mathrm{erg} / \mathrm{deg} / \mathrm{mole}, R=1.987 \mathrm{cal} / \mathrm{deg} /$ mole, $h=6.625 \times 10^{-27}$ erg sec, $\Phi=0.166, \Delta S=$ change in entropy, $E=$ activation energy from graph.

(ii)

$$
\Delta F=\Delta H-T \Delta S
$$

where, $\Delta H=$ Enthalpy change $=$ Activation energy, $T=$ Temperature in $\mathrm{K}, \Delta S=$ Entropy change \{from (i) used\}.

(iii) Frequency factor

$$
\begin{gathered}
B_{2 / 3}=\frac{\log Z E_{\mathrm{a}}}{R \Phi}, \\
B_{2 / 3}=\log 3+\log [1-3 \sqrt{1-\alpha}]-\log p(x),
\end{gathered}
$$

where, $Z$ = Frequency factor, $B=$ Calculated from (8), $\log p(x)=$ Calculated from Doyle table corresponding to activation energy.

(iv) Apparent entropy change:

$$
S^{*}=2.303 R \log \frac{Z h}{\mathrm{R} T^{*}}
$$

where, $Z$ = from relation $(7), T^{*}=$ Temperature at which half of the compound is decomposed from it total loss.

By using the data of the Freeman-Carroll method, various thermodynamics parameters have been calculated (Table 2). From the abnormally low values of frequency factor, it may be concluded that the decomposition reaction of 8-HQ5-SAMF-IV terpolymer resin can be classed as a "slow" reaction. There is no other obvious reason $[23,24]$.

Fairly good straight line plots are obtained using two methods. This is expected since the decomposition of terpolymer is known not to obey first-order kinetics perfectly $[23,24]$.

\section{Conclusions}

(1) A terpolymer 8-HQ5-SAMF-IV, based on the condensation reaction of 8-hydroxyquinoline 5-sulphonic acid-melamine-formaldehyde in the presence of acid catalyst, was prepared.

(2) As the degradation of the terpolymer under investigation started at high temperature which indicates that the terpolymer 8-HQ5-SAMF-IV is thermally stable at elevated temperature.

(3) Low value of frequency factor may be concluded that the decomposition reaction of 8-hydroxyquinoline 5sulphonic acid-melamine-formaldehyde terpolymer resin-IV can be classified as "slow reaction".

\section{Acknowledgments}

The authors are grateful to the director of LIT, RTM Nagpur University, Nagpur, and the Head of the Department of Chemistry, LIT, RTM Nagpur University, Nagpur, for providing laboratory facility. They are also thankful to the director of SAIF, Punjab University, Chandigarh.

\section{References}

[1] K. Hajime, M. Youchi, M. Akihiro et al., "New thermosetting resin from terpenediphenol-based benzoxazine and epoxy resin," Journal of Applied Polymer Science, vol. 74, no. 9, pp. 2266-2273, 1999.

[2] W. B. Gurnule, H. D. Juneja, and L. J. Paliwal, "Ion-exchange properties of 8-hydroxyquinoline-biuret-formaldehyde tercopolymers," Indian Journal of Chemistry, vol. 39, no. 10, pp. 1110-1113, 2000.

[3] P. K. Rahangdale, W. B. Gurnule, L. J. Paliwal, and R. B. Kharat, "Chelation ion-exchange properties of a copolymer derived from 2-hydroxyacetophenone, oxamide, and formaldehyde," Synthesis and Reactivity in Inorganic and Metal-Organic Chemistry, vol. 33, no. 7, pp. 1187-1205, 2003.

[4] D. K. Rath, P. L. Nayak, and S. Lenka, "Synthetic resins. XIV. Chelation ion exchange properties of 2, 4-dinitro phenylhydrazone of 2-hydroxy acetophenone-formaldehyde resin," Journal of Applied Polymer Science, vol. 51, no. 9, pp. 16791682, 1994.

[5] U. K. Samal, P. L. Nayak, and S. Lenka, "Synthetic resins. XXI. Ion-exchange properties of the resins derived from oximes of 2-hydroxy acetophenone-substituted benzoic acidformaldehyde," Journal of Applied Polymer Science, vol. 47, no. 8, pp. 1315-1317, 1993.

[6] Z. Slanina and L. A. Tokarova, "On thermodynamics of the gas-phase isomeric heterodimers of nitrous oxide and hydrogen fluoride," Thermochimica Acta, vol. 197, no. 1, pp. 181$189,1992$.

[7] Z. Hong, W. Yu-Zhang, W. Xui-Li et al., "Kinetics of thermal degradation of flame retardant copolyesters containing phosphorus linked pendent groups," Polymer Degradation and Stability, vol. 80, no. 1, pp. 135-140, 2003.

[8] W. B. Gurnule, P. K. Rahangdale, J. Paliwal, and R. B. Kharat, Journal of Applied Polymer Science, vol. 89, no. 3, p. 886, 2003.

[9] W. B. Gurnule, P. K. Rahangdale, L. J. Paliwal, and R. B. Kharat, "Synthesis, characterization and ion-exchange properties of 4-hydroxyacetophenone, biuret and formaldehyde terpolymer resins," Reactive and Functional Polymers, vol. 55, no. 3, pp. 255-265, 2003.

[10] R. N. Singru, A. B. Zade, and W. B. Gurnule, "Synthesis, characterization, and thermal degradation studies of copolymer resin derived from p-cresol, melamine, and formaldehyde," Journal of Applied Polymer Science, vol. 109, no. 2, pp. 859-868, 2008.

[11] P. E. P. Michael, J. Barbe, H. D. Juneja, and L. J. Paliwal, "Synthesis, characterization and thermal degradation of 8-hydroxyquinoline-guanidine-formaldehyde terpolymer," European Polymer Journal, vol. 43, no. 12, pp. 4995-5000, 2007.

[12] P. K. Rahangdale, W. B. Gurnule, L. J. Paliwal, and R. B. Kharat, "Synthesis and characterization of copolymer derived from 2hydroxyacetophenone, oxamide and formaldehyde," Progress in Crystal Growth and Characterization of Materials, vol. 45, no. 1-2, pp. 155-160, 2002. 
[13] R. M. Joshi and M. M. Patel, Indian Journal of Chemistry A, vol. 28, pp. 55-58, 1989.

[14] J. R. Patel, D. H. Sutaria, and M. N. Patel, "Poly[1,3(2ethoxy-4-hydroxy-5-propylphenylene)propylene] copolymer as an ion exchanger," High Performance Polymers, vol. 6, no. 3, Article ID 003, pp. 201-208, 1994.

[15] W. B. Gurnule, H. D. Juneja, and L. J. Paliwal, "Synthesis and characterization of 8-hydroxyquinoline-melamine-formaldehyde terpolymers," Asian Journal of Chemistry, vol. 12, no. 1, pp. 51-57, 2000.

[16] R. M. Silverstein, G. C. Bassler, and T. C. Morrill, Spectrometric Identification of Organic Compounds, John Wiley \& Sons, Singapore, Republic of Singapore, 5th edition, 1991.

[17] P. K. Rahangdale, W. B. Gurnule, L. J. Paliwal, and R. B. Kharat, "Chelation ion-exchange properties of a copolymer derived from 2-hydroxyacetophenone, oxamide, and formaldehyde," Synthesis and Reactivity in Inorganic and Metal-Organic Chemistry, vol. 33, no. 7, pp. 1187-1205, 2003.

[18] R. K. Samal, B. K. Senapati, and T. B. Behuray, "Synthesis and characterization of aniline-doped mixed copolymer resins. II," Journal of Applied Polymer Science, vol. 62, no. 4, pp. 655-660, 1996.

[19] B. S. Furniss, A. J. Hannaford, P. W. G. Smith, and A. R. Tatchell, Vogel's Textbook of Practical Organic Chemistry, Addison-Wesley/Longman, England, UK, 1998.

[20] R. T. Morrison and R. N. Boyd, Organic Chemistry, Prentice Hall, New Delhi, India, 6th edition, 1996.

[21] G. Barth Howard and W. Mays Jimmy, Modern Methods of Polymer Characterization, John Wiley \& Sons, New York, NY, USA, 1991.

[22] A. S. Aswar, R. G. Mahale, P. R. Kakde, and S. G. Bhadange, "Structural, thermal and electrical studies on cobalt-, nickel-, copper-, zinc- and cadmium(II) complexes," Journal of the Indian Chemical Society, vol. 75, no. 7, pp. 395-397, 1998.

[23] N. A. Mohamed and A. O. Hamad Al-Dossary, "Structureproperty relationships for novel wholly aromatic polyamidehydrazides containing various proportions of para-phenylene and meta-phenylene units II. Thermal stability and degradation behaviour," Polymer Degradation and Stability, vol. 79, no. 1, pp. 61-75, 2003.

[24] P. K. Rahangdale, L. J. Paliwal, and R. B. Kharat, "Thermal and electrical studies of terpolymer resins derived from 4hydroxy acetophenone, oxamide and formaldehyde," Transactions of Society for Advancement of Electrochemical Science and Technology, vol. 35, no. 1, pp. 16-18, 2000. 

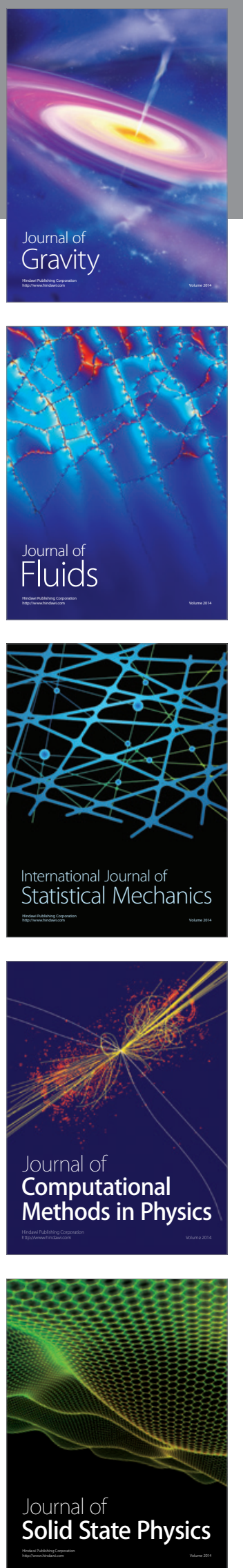
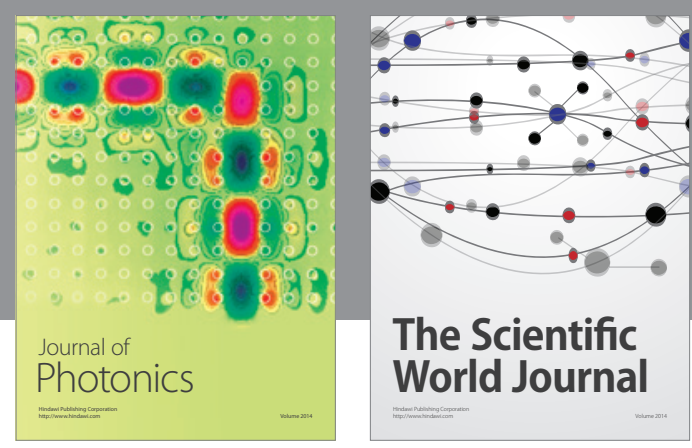

The Scientific World Journal

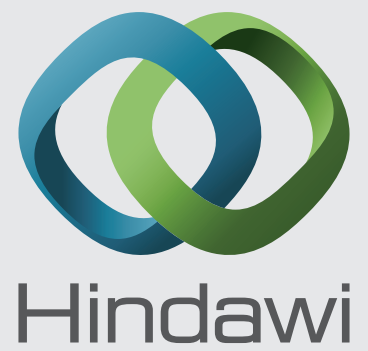

Submit your manuscripts at http://www.hindawi.com
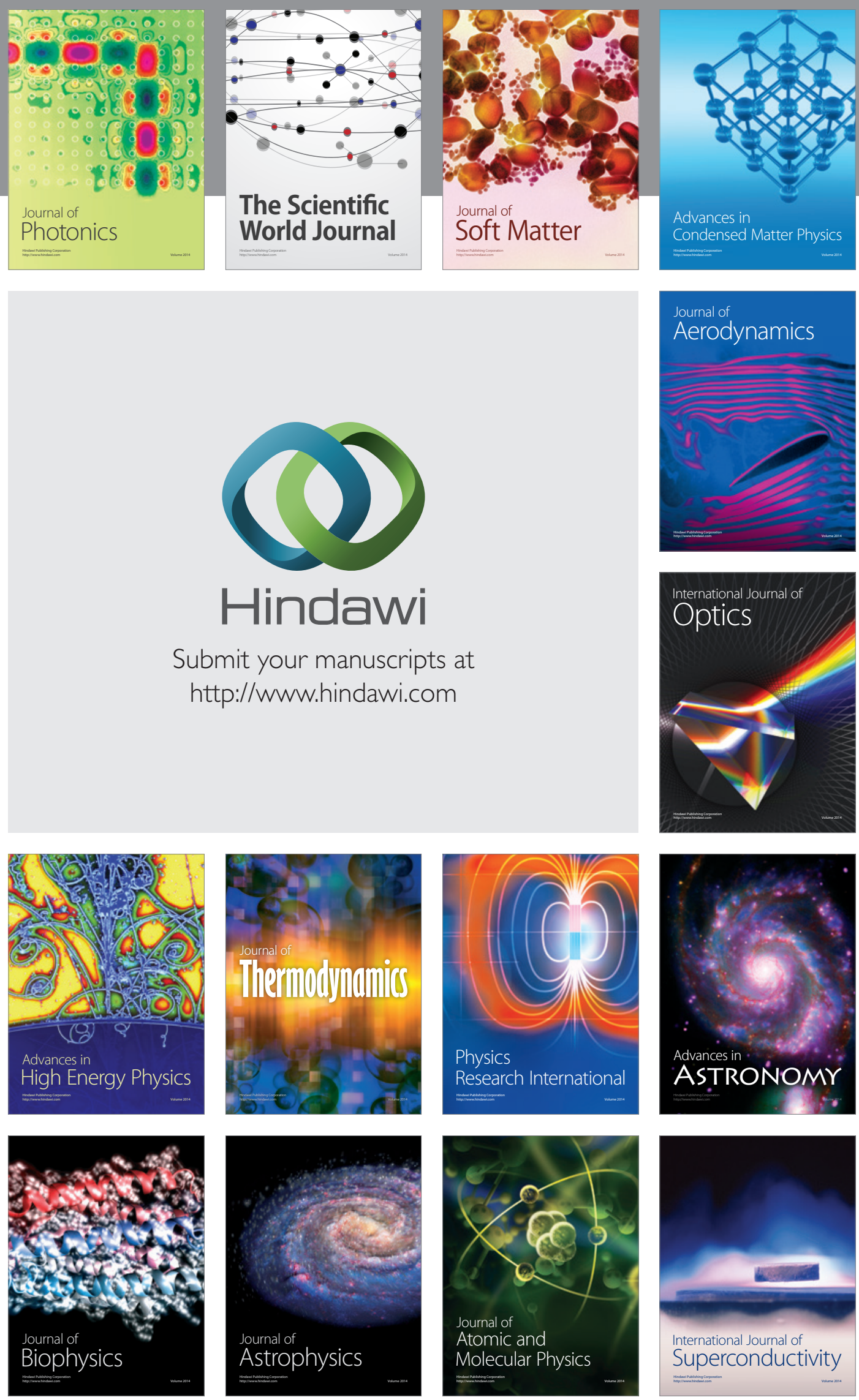
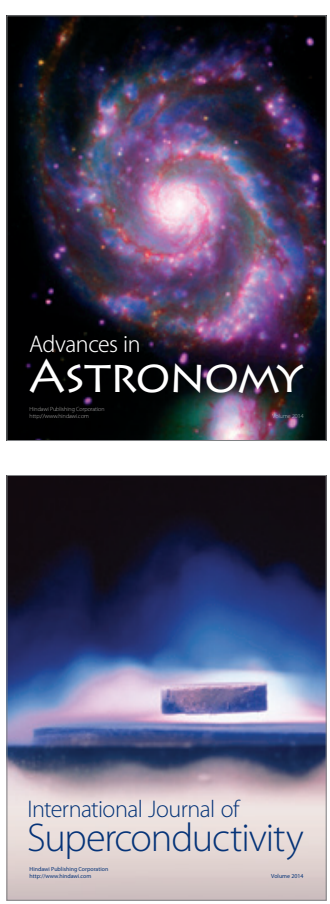